\title{
Characteristics and health care costs in patients with a diagnostic imaging for low back pain in Switzerland
}

\author{
Stefania Di Gangi ${ }^{1} \cdot$ Christophe Bagnoud $^{2} \cdot$ Giuseppe Pichierri $^{1} \cdot$ Thomas Rosemann $^{1} \cdot$ Andreas Plate $^{1}$
}

Received: 18 March 2021 / Accepted: 21 October 2021 / Published online: 30 October 2021

(c) The Author(s) 2021

\begin{abstract}
Low back pain (LBP) is one of the most common musculoskeletal disorders worldwide and a frequent cause for health care utilization with a high economic burden. A large proportion of diagnostic imaging in patients with LBP is inappropriate and can cause more harm than good, which in turn can lead to higher health care costs. The aim of this study was to determine characteristics and health care costs for patients with a diagnostic imaging for LBP in Switzerland. Groupe Mutuel, one of the biggest health care insurance companies in Switzerland and covering approximately $12 \%$ of the population, provided data for this analysis. Patients were identified by diagnostic imaging for the lumbar spine in 2016 or 2017 . The study period was 2015-2019, that is one year before and two years after the year of imaging. Regression analysis models were used to identify patient variables associated with higher health care costs. A total of 75,296 patients (57\% female, mean age: 54.5 years) were included into the study. Magnetic resonance imaging was the most commonly used diagnostic method (44.3\%). Patients generated annual mean health care costs of 518,488,470 CHF (466,639,621 Euro) in the whole observation period; 640 million CHF (576 million Euro) in the index year. Overall, costs for LBP patients were $72 \%$ higher compared with the costs of no LBP patients. Our findings confirm the economic burden of LBP and highlight the importance of ongoing efforts to improve prevention, diagnostics and patient care in patients with LBP.
\end{abstract}

Keywords Low back pain $\cdot$ Characteristics $\cdot$ Diagnostic imaging $\cdot$ Economic burden $\cdot$ Health care costs

JEL Classification I13

\section{Introduction}

Acute non-specific low back pain (LBP) is one of the most common musculoskeletal disorders worldwide [1-3]. With a lifetime prevalence of up to $80 \%$ [4, 5], LBP entails a high social burden. Despite the individual burden of affected patients, health care costs of LBP are of particular interest and various studies using quite different methodological approaches report estimates of costs of patients with LBP [6]. Due to the different health care systems and cultural

Stefania Di Gangi and Christophe Bagnoud Co-Shared First authorship.

Stefania Di Gangi

stefania.digangi@usz.ch

1 Institute of Primary Care, University and University Hospital Zürich, Pestalozzistrasse 24, 8091 Zürich, Switzerland

2 Groupe Mutuel, Martigny, Switzerland factors, health care costs may differ greatly between countries [3]. Switzerland is one of the countries with the highest health care spending in the world [7] and a study published in 2011 estimated the total yearly costs of LBP in Switzerland to 6.6 Billion Euro, which corresponds to $2.3 \%$ of the national gross domestic product (GDP) [8].

Radiological imaging is an important cost driver in the context of LBP [9]. Even if not always necessary in many acute LBP cases, radiological imaging is a common part of the patient workup [10]. The images themselves cause health care costs and incidental findings, requiring further investigations, generate further health care costs. This is one reason, why various guidelines promoting good clinical practice are available [10] and the recommendation of avoiding unnecessary radiological imaging is one of the most prominent messages of both international and national choosing wisely campaigns $[11,12]$. In addition, a range of further comorbidities like depression, anxiety or sleep 
disorders has shown to be associated with LBP [13], thus contributing to increased health care costs in this population.

This combination of high LBP-associated costs and concomitant high prevalence, illustrates that monitoring health care costs, and not only LBP specific costs, and identifying patients with a risk of increasing costs is of utmost importance. Analyses that specifically report the total health care costs of patients with diagnostic imaging for LBP, and not only the specific LBP-associated costs, are lacking. The fact that a large proportion of diagnostic imaging is inappropriate also highlights the importance of such analyses. With this knowledge, health care providers, insurance companies and official health authorities can improve strategies and interventions fostering prudent patient care, which in turn can contribute to limit rising health care costs.

The objective of the present study was to determine patient characteristics and actual data on the health care costs for patients with a diagnostic imaging for LBP in Switzerland using health claims data provided by a national health insurance company. In addition, we aim to determine the incremental health care costs due to LBP.

\section{Material and methods}

\section{Study design and database}

In this retrospective observational study, we analysed health care data provided by Groupe Mutuel (GM). GM is one of the largest health insurance company in Switzerland, covering approximately $12 \%$ of the total Swiss population in 2016 and 2017. GM insures patients in all parts of Switzerland, although a higher proportion of the population is insured in the French-speaking part of Switzerland (up to one-third of the population). Due to applicable regulations provided by GM, we analysed a random selected subset of around $92 \%$ of all identified patients.

\section{Inclusion criteria and definitions}

We identified patient costs of LBP using tarif medical (TARMED) codes coding imaging methods of the spine as a surrogate for LBP. TARMED codes were used to code all medical procedures for reimbursement in the Swiss outpatient setting. We included patients by (i) specific TARMED codes for the lumbar spine (39.0150 and 39.0155 [x-ray of the spine, first image, and further images]), and (ii) unspecific TARMED codes for the spine (39.4100 [computed tomography (CT) of the spine]), and 39.5060 [magnetic resonance imaging (MRI) of the spine]). We included all patients $\geq 18$ years of age.

To prevent incorrect inclusion of patients based on nonspecific codes, we excluded patients from the analysis if they had an unspecific imaging code (CT or MRI) in combination with a specific TARMED code for an adjacent anatomic region (for example combined TARMED codes for CT of the spine and CT of the skull). These combinations, in fact, could indicate that the pathology was not exclusively related to the lumbar spine. Furthermore, patients with a back surgery in the year before and after the index imaging were excluded.

A full list of exclusion codes was provided in Exclusion codes, Supplementary Information. For the analysis we included all patients with an imaging in the year 2016 or 2017 (index years). For each included patient, data one year before and two years after the index year, 4 years in total, were provided by GM. Accordingly, the data evaluated were from 2015 to 2019 . The long observation period was chosen to reliably identify and exclude patients without non-specific LBP and to map the costs over a longer period. If patients had images in both index years, we grouped the patients according to the imaging in the first index year and reported baseline characteristics based on the first year of index imaging only.

In Switzerland, all citizens have a compulsory health insurance that covers medical treatments and thus there is no distinction between a public and private system. Insured persons had a deductible for their health care insurance. We defined three levels of deductible amounts: level $1: \leq 500$ Swiss Francs (CHF), level 2: 501-1500 CHF, and level 3: 1501-2500 CHF. Average price 2019: 1 Swiss Franc $\approx 0.90$ Euro [14]. In addition, two main models of health care insurances, which could predict health care costs were: managed care insurance and free choice model. In the first one, a healthcare manager (a family doctor [family physician model], a network [network model] or a specialized telemedicine call-centre [telemedicine model]) acts as a gatekeeper. In the second one, insurers have full freedom to receive treatment from doctors and specialists of their choice.

Pharmaceutical cost groups (PCG) were used as a surrogate marker for existing comorbidities. The PCG system is based on the linkage between medication, defined by Anatomical Therapeutic Chemical Classification System (ATC) codes, and specific diagnosis (for example, the use of insulin as a surrogate for diabetes mellitus) and it is used to identify patients with cost-intensive chronic diseases [15]. Moreover, as a possible factor influencing costs, we considered the language spoken in the area of patient residence. In Switzerland, in fact there are three official languages at national level: German, French, and Italian. Some Swiss cantons are bilingual and in these cases we considered the language spoken by the majority of the population. To account also for patients whose residence was abroad, we grouped the area of residence into four categories: German, French, Italian and abroad. 


\section{Health care costs (outcomes)}

The overall costs for LBP included all invoices that were reimbursed within the framework of compulsory health insurance, including the cost-sharing of the insured persons. TARMED tariff values were calculated by dividing claims in Swiss Francs by a reimbursement factor for medical services, negotiated annually between medical associations, health insurers, and health authorities on a cantonal level.

In addition to the overall costs, costs for pain medications, LBP-associated additional co-medications and medical services were analysed. Pain medications and LBP-associated additional co-medications (muscle relaxants, proton pump inhibitors, laxatives, sleeping pills, and antidepressants) were identified using the ATC codes. All used ATC codes, within the ATC code list, for (i) pain medication and (ii) other medications were provided as Supplementary Information. The annual average number of prescribed items per patients was also reported together with the costs of pain and additional medication. Medical services included all settled costs in the context of health care utilization, excluding physicians and hospitals, i.e.: occupational therapy, physiotherapy, care services, rehabilitation, assist devices, or complementary medicine. The annual average number of medical service consultations per patient was reported.

To determine incremental costs for patients with LBP, we analysed mean health care costs for patients with LBP (separately for both index years) and compared the costs with a one-to-one matched random sample of the general population without LBP, insured by GM. All patients were at least matched by age and sex. In addition, 60,699 (80.6\%) patients could be matched by the following additional variables: canton of residence, type of health care insurance, deductible and all 34 different comorbidities listed in supplemental Table S2 (full matches). If a full match was not possible, we matched patients by all above-mentioned variables and presence of comorbidities overall (dichotomous variable yes/no) (11,810 patients, $15.7 \%)$. The remaining patients were matched by age, sex, type of insurance, and presence of comorbidities overall $(n=2779,3.7 \%)$, or age, sex, and presence of comorbidities overall $(n=8,<0.1 \%)$.

All costs were described and reported annually, in particular for the index year, and as average of the 4-year period. Costs were reported split by index year cohort or combined. In the latter case, the sum or the average by index year, was considered, respectively, for total costs and patient level costs. Since data were collected from different years (2015 to 2019), all costs were adjusted to the same reference year (2019) using consumer price index to let costs comparable. Consumer Price Index (CPI) for Switzerland in 2015-2019 were taken from [16] and reported in Consumer Price Index and Inflation rates (2015-2019), Supplemental Information. Costs were expressed in Swiss Francs but to let costs comparable with the ones in the European context, we converted and reported the main results into Euro (EUR) too, adjusting also for price levels indices for health care services [17] in Switzerland in 2019 with reference to the European Union average price level. Comparative price levels for health sector were taken from Eurostat [18]. CPI, inflation rates and adjusting factors are reported in the Supplemental Information, Table S3.

\section{Statistics}

Descriptive statistics of basic characteristics of the patients were reported as number (percentage \%) or means (standard deviation $[\mathrm{SD}]$ ) where appropriate. Group comparisons by diagnostic image and by index year were performed using Chi-square tests, for categorical variables, or ANOVA test, for continuous variables (for example age). Patient characteristics considered were: age, sex, survival status, language spoken in canton of residence, health insurance model and relative deductible, comorbidities, use of medical service and in-hospital treatment. Mortality rate of LBP patients was compared with the mortality rates of the general population, whose calculation was based on $[19,20]$. Health care costs, total and per patient, specific for index year only or as average of the four year period, were presented overall, by index year and diagnostic imaging. Costs group comparisons were performed through ANOVA tests. In order to account for the skewed data, bootstrap resampling method, case bootstrap, was used to compute p-values.

A multivariable mixed model with patients as random effects (intercept) and correction for autocorrelation, autoregressive moving average ARMA $(1,1)$, was implemented to study the association of patient variables with the average yearly cost per patient. Details of the model were provided in Statistical model description, Supplementary Information. Patient characteristics, described above, were considered into the model together with the index imaging year (2016 or 2017) and the time from index imaging. Effect of time, from index imaging, was not linear on costs. Therefore, a quadratic trend was used. We also considered in the model, as fixed effect, the interaction term between the type of insurance and the deductible. To address skewed data, results of the regression were estimates and confidence intervals computed using bootstrap resampling method for mixed models (case bootstrap with resampling at patient level) [21].

For group comparisons of costs and for the regression analysis, patients with images in both index years were excluded to avoid overestimation. However, as additional analysis, for these patients the trend of annual costs, during all the study period, was showed graphically by type of index imaging in both index years.

Annual costs for LBP patients compared with annual costs for no LBP patients depending on age were showed 
graphically for all patients matched at least by age and sex. A regression analysis of annual costs of the two subgroups, with full matches including comorbidities, is provided as Supplemental Information, Table S4. In the latter analysis, patients with two or more comorbidities were excluded because information on the costs split by comorbidities was missing. Results of all regression analyses were reported as estimates and $95 \%$ confidence intervals.

For all tests, $P \leq 0.05$ was considered statistically significant. All analyses were carried out using statistical package R (https://www.R-project.org).

\section{Ethics}

Analysing full anonymized and aggregated data from health care insurances did not fall under the Swiss Federal Act on Research involving Human Beings (Human Research Act) and thus no ethics approval was needed.

\section{Results}

\section{Basic characteristics}

We included 75,296 patients in our analysis (Fig. 1) for both index years combined. Patients with any imaging of the spine corresponded to $4.4 \%$ of all insured patients in the index year. The mean age was 54.5 years (SD 16.4 years) and $57 \%$ were female.

Most of the patients were from the French (56\%), and German-speaking part (39.4\%) of Switzerland. A proportion of $17.5 \%$ had an in-hospital treatment during the observation period. An MRI of the spine was the most common imaging method (44.3\%), followed by X-ray (32.5\%) and a combination of X-ray/CT imaging (11.3\%). We found statistically significant differences in all analysed variables in dependence of the type of index imaging ( $p<0.001$ for all variables). Patients with a CT imaging were older and had more comorbidities compared to patients with an X-ray or MRI imaging. In addition, both the proportion of deceased and the mortality rate compared to the general population were highest in patients with a CT (Table 1 and Supplementary Information Table S1). A detailed table of comorbidity frequencies overall and by diagnostic imaging is provided in Table S2, Supplementary Information.

Regarding year of index imaging, in 2017, compared to 2016, we found significantly higher proportion of patients in the German area $(p=0.012)$, significantly higher proportion of telemedicine insurance model and highest franchise $(p<0.001)$. In contrast, we found significantly lower proportion of comorbidities, deceased and use of medical services $(p<0.001)$.

\section{Health care costs}

Main health care costs are presented in in Table 2 (in CHF) and in Supplemental Information Table S3 (in EUR). The sum of the annual health care costs (averaged on the whole observation period of 4 years and for the two groups based on index imaging 2016 and 2017) was around 518 million CHF (467 million EUR), 628 million CHF (565 million EUR) including patients with two index imaging in 2016 and 2017. Overall costs for patients, relative only to the year of index imaging, were 319,590,507 CHF $(287,631,456 \mathrm{EUR})$; ambulatory: 266,310,563 CHF (239,679,507 EUR), in-hospital: 53,279,944 CHF (47,951,950 EUR) for group 2016, $\mathrm{n}=34,404$ patients, and $320,910,867$ CHF $(288,819,780$ EUR); ambulatory: 268,191,856 CHF (241,372,670 EUR), in-hospital: 52,719,011 CHF (47,447,110 EUR) for group $2017, n=33,555$ patients.

The mean annual health insurance costs per patient, regardless of the type of index imaging and index year was 8722 CHF (7850 EUR) for the whole observation period. Annual costs for patients with only one index imaging, in relation to the index year and the type of diagnostic imaging are presented in CHF, Table 2. The main results converted in EUR, adjusted for the European Union average price level indices in health sector in 2019, are shown in Supplemental Table S3. Lowest mean costs per patient were observed in patients with an X-ray as index imaging, $8112 \mathrm{CHF}$ (7301 EUR), and highest in patients with a CT + X-ray, 13,142 CHF (11,828 EUR). This pattern of costs distribution was almost the same for each type of expense in our analysis: patients with only X-ray imaging had the lowest costs, whereas patients with $\mathrm{X}$-ray and additional CT imaging the highest costs.

The individual costs for analgesic drugs, during the index year, ranged from 105.10 CHF (94.59 EUR), for patients with X-ray, to 193.67 CHF (174.30 EUR) for patient with $\mathrm{X}$-ray and CT. The costs for additional drugs in the index year ranged from 157.96 CHF (142.16 EUR), for patients with MRI, to 207.99 CHF (187.19 EUR) for patients with $\mathrm{X}$-ray and CT. Costs for medical services were lowest in the X-ray group and highest in the CT group: $1602.78 \mathrm{CHF}$ (1442.50 EUR) vs 2698.29 CHF (2428.46 EUR) in the index year. Mean costs of all patients over the whole observation period were plotted as points in Fig. 2. Costs for patients with the index imaging in 2017 were slightly higher compared to the costs for patients with the index imaging in 2016. In general, costs were highest in the year of index imaging.

An additional analysis for the 7337 patients with a double index imaging in 2016 and 2017 is reported in Fig S1, Supplementary Information. Over all observation period, in this patient subgroup the costs were higher compared to the ones of the patients with a single index imaging. 


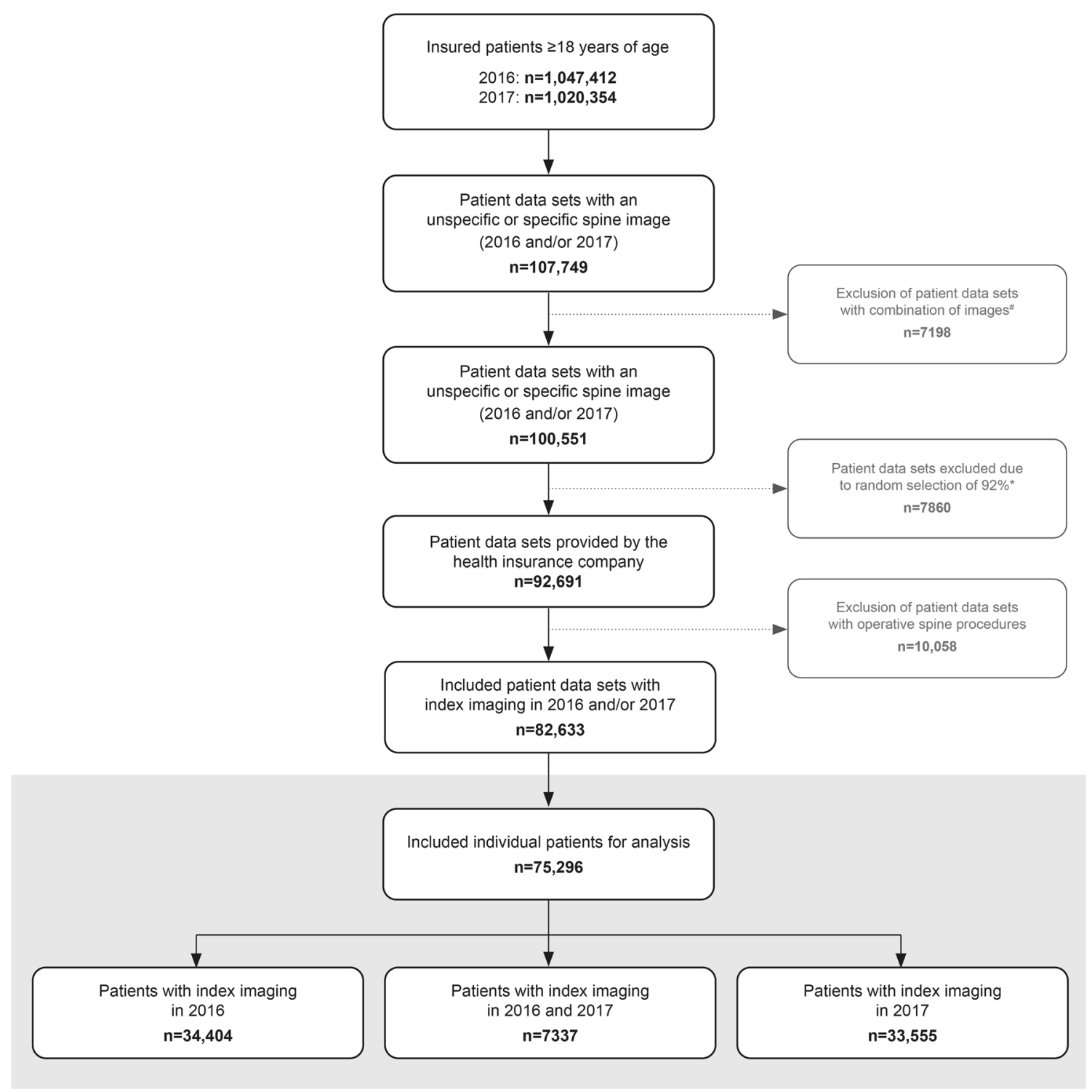

Fig. 1 Flowchart of 75,296 eligible patients with an index imaging in 2016 and / or 2017. Patient exclusions are described in the boxes to the right: "patients with an unspecific radiological image (computed tomography $[\mathrm{CT}]$ or magnetic resonance imaging) of the spine and a simultaneous radiological image of an adjacent anatomical region were excluded (for example CT of the spine and CT of the shoulder).

\section{Regression modelling}

Patient variables and their association to the overall costs, at patient level, are analysed in Table 3 and Supplementary Information, Table S4. The use of medical services and the presence of comorbidities were associated with the highest increase in costs: 2540 CHF (2286 EUR) and 6178 CHF (5560 EUR), respectively. On the other hand, living outside the French-speaking part of Switzerland and having an insurance model with a gatekeeper function
*Due to applicable regulations provided by the health care insurance, a random selected subset of around $92 \%$ of all identified patients could be analysed. Grey shaded area: detailed description of individual patients (versus patient data sets in which patients may be listed twice, if index imaging was in 2016 and 2017)

were associated with lower costs. Moreover, the regression results confirmed the significant highest costs $(p<0.001)$ in patients with a CT $+\mathrm{X}$-ray. Fitted values of the model, by diagnostic imaging and index imaging group (2016 vs. 2017) are shown in Fig. 2. Within the comorbidities variable, for patients with only one comorbidity matched with no LBP patients, we found a heterogeneous distribution of costs ranging from $868 \mathrm{CHF}$ (781 EUR) for cardiovascular diseases up to $35,465 \mathrm{CHF}(31,918 \mathrm{EUR})$ for cancer, Supplementary Information, Table S4. 
Table 1 Basic characteristics of 75,296 patients according to the index year and the type of diagnostic image in the index year

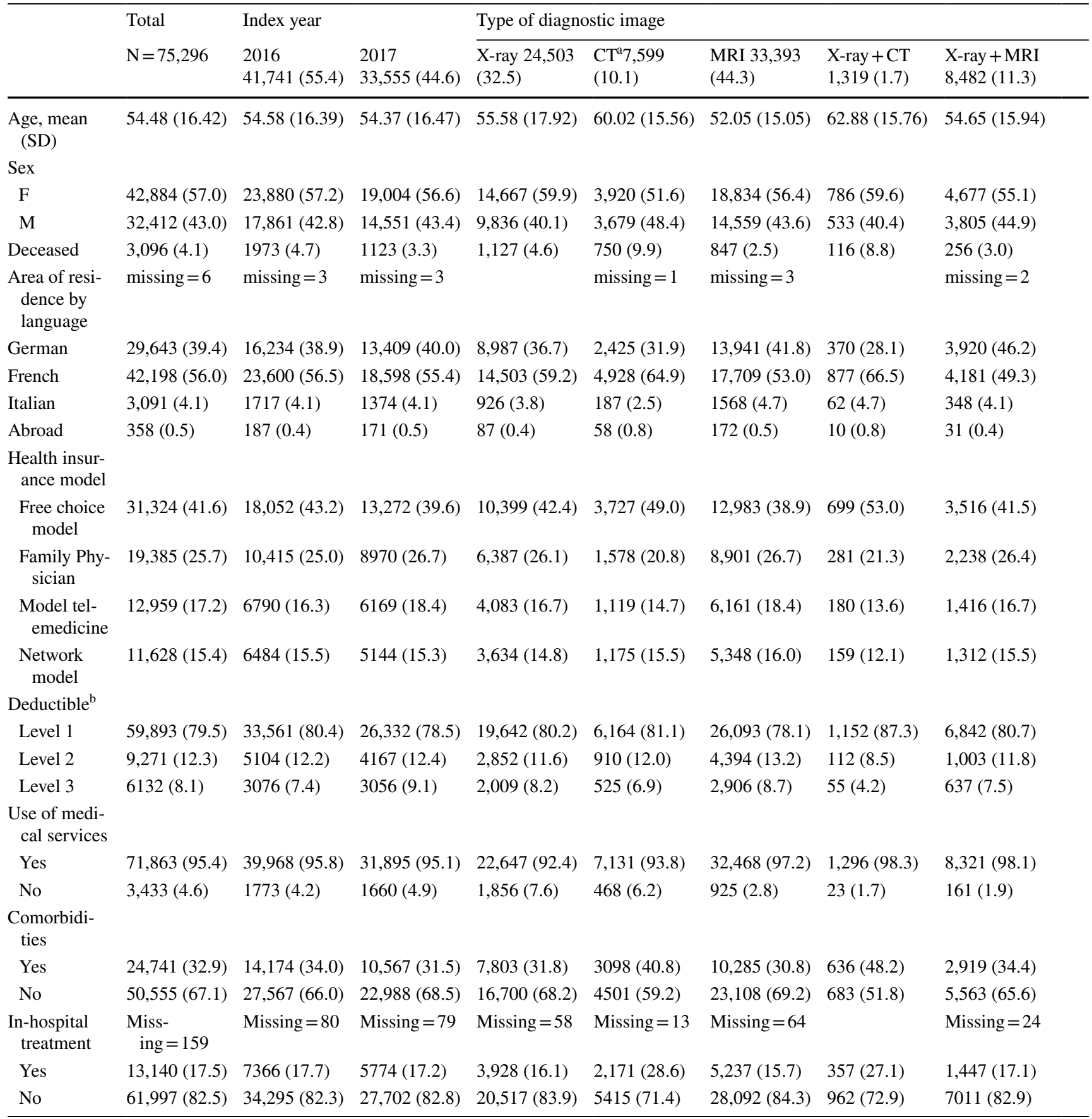

If not stated else, variables are presented as absolute numbers and percentages (in parentheses)

${ }^{a} C T$ computed tomography, $M R I$ magnetic resonance imaging, $S D$ standard deviation, $N$ number of patients, $F$ female, $M$ male

${ }^{\mathrm{b}}$ Deductible levels: level 1: $\leq 500$ Swiss francs (CHF), level 2: 501-1500 CHF, and level 3: 1501-2500 CH

\section{Estimation of incremental costs}

Health care costs relative to a population of no LBP insured persons, randomly matched by a one-to-one allocation, are shown in Fig. 3. In patients $\leq 90$ years of age, the average health care costs for LBP patients were higher than the average costs of no LBP insured persons with an absolute difference ranging from 852 to $7642 \mathrm{CHF}$ (767-6878 EUR), in 2016, and from 1232 to 6467 CHF (1109-5820 EUR), in 2017 , and an overall relative difference of $82 \%$ of the average costs for no LBP patients. For patients aged above 90 years, the overall difference of $9 \%$ was not significant. 
Table 2 Annual health care costs (in Swiss Francs, CHF) for all patients with only one index imaging

\begin{tabular}{|c|c|c|c|c|c|c|}
\hline & Total/overall & X-ray & $\mathrm{CT}$ & MRI & $\mathrm{X}$-ray and CT & X-ray and MRI \\
\hline Number of patients ${ }^{\mathrm{a}}$ & 67,959 & 22,474 & 6537 & 30,392 & 1062 & 7494 \\
\hline Cohort 2016 & 34,404 & 11,579 & 3150 & 15,274 & 536 & 3865 \\
\hline Cohort 2017 & 33,555 & 10,895 & 3387 & 15,118 & 526 & 3629 \\
\hline Overall annual costs ${ }^{\mathrm{b}}$ & $518,488,470$ & $158,572,216$ & $70,727,315$ & $218,641,017$ & $12,583,619$ & $57,964,303$ \\
\hline Total: cohort $2016^{\mathrm{c}}$ & $258,863,732$ & $80,942,939$ & $32,608,029$ & $110,145,440$ & $6,381,625$ & $28,785,698$ \\
\hline Total: cohort $2017^{\mathrm{c}}$ & $259,624,738$ & $77,629,276$ & $38,119,286$ & $108,495,576$ & $6,201,994$ & $29,178,605$ \\
\hline Ambulatory: cohort 2016 & $212,603,762$ & $65,020,098$ & $25,649,547$ & $93,068,012$ & $5,116,691$ & $23,749,414$ \\
\hline Ambulatory: cohort 2017 & $213,846,043$ & $63,203,610$ & $30,347,419$ & $91,357,092$ & $4,766,658$ & $24,171,264$ \\
\hline In-hospital: cohort 2016 & $46,259,970$ & $15,922,841$ & $6,958,483$ & $17,077,429$ & $1,264,933$ & $5,036,285$ \\
\hline In-hospital: cohort 2017 & $45,778,695$ & $14,425,666$ & $7,771,867$ & $17,138,484$ & $1,435,336$ & $5,007,341$ \\
\hline Individual: cohort $2016^{\mathrm{d}}$ & 8571 & 8008 & 11,590 & 8214 & 13,178 & 8496 \\
\hline Individual: cohort $2017^{\mathrm{d}}$ & 8878 & 8223 & 12,687 & 8256 & 13,105 & 9169 \\
\hline Individual subgroup: cohort $2016^{\mathrm{e}}$ & 22,849 & 23,144 & 24.373 & 22,175 & 26,523 & 21,325 \\
\hline Individual subgroup: cohort $2017^{\mathrm{e}}$ & 23,447 & 22,305 & 27,321 & 22,936 & 24,791 & 21,770 \\
\hline Individual index year cost: $2016^{\mathrm{f}}$ & 9289 & 7977 & 14,091 & 9031 & 14,324 & 9632 \\
\hline Individual index year cost: $2017^{\mathrm{f}}$ & 9564 & 8113 & 14,906 & 9157 & 14,976 & 9844 \\
\hline Costs for imaging ${ }^{g}$ & $18,180,182$ & 639,463 & $1,778,577$ & $12,191,754$ & 315,636 & $3,254,751$ \\
\hline Individual index year cost: 2016 & 261 & 28 & 270 & 394 & 297 & 420 \\
\hline Individual index year cost: 2017 & 274 & 29 & 274 & 409 & 298 & 450 \\
\hline Pain medication costs & $5,245,791$ & $1,480,829$ & 596,017 & $2,305,477$ & 147,592 & 715,876 \\
\hline Individual: cohort 2016 & 126 & 110 & 160 & 122 & 201 & 152 \\
\hline Individual: cohort 2017 & 122 & 109 & 137 & 122 & 192 & 137 \\
\hline Quantity of prescriptions: cohort $2016^{\mathrm{h}}$ & 6 & 6 & 8 & 6 & 8 & 7 \\
\hline Quantity of prescriptions: cohort $2017^{\mathrm{h}}$ & 6 & 6 & 6 & 6 & 9 & 7 \\
\hline Individual index year cost: 2016 & 124 & 105 & 159 & 120 & 189 & 156 \\
\hline Individual index year cost: 2017 & 122 & 105 & 134 & 122 & 198 & 144 \\
\hline Additional medication costs & $5,906,696$ & $1,831,683$ & 673,056 & $2,534,470$ & 139,053 & 728,434 \\
\hline Individual: cohort 2016 & 183 & 182 & 206 & 175 & 221 & 190 \\
\hline Individual: cohort 2017 & 180 & 183 & 200 & 171 & 221 & 184 \\
\hline Quantity of prescriptions: cohort $2016^{\mathrm{h}}$ & 5 & 5 & 6 & 5 & 6 & 6 \\
\hline Quantity of prescriptions: cohort $2017^{\mathrm{h}}$ & 5 & 5 & 6 & 5 & 7 & 5 \\
\hline Individual index year cost: 2016 & 167 & 168 & 195 & 159 & 202 & 171 \\
\hline Individual index year cost: 2017 & 167 & 170 & 196 & 157 & 214 & 167 \\
\hline Costs for medical services & $84,521,978$ & $24,180,027$ & $9,276,552$ & $38,413,941$ & $1,893,809$ & $10,757,649$ \\
\hline Individual: cohort 2016 & 1889 & 1746 & 2266 & 1857 & 2447 & 2021 \\
\hline Individual: cohort 2017 & 1951 & 1794 & 2172 & 1929 & 2483 & 2194 \\
\hline Number of consultations: cohort $2016^{i}$ & 14 & 12 & 13 & 14 & 19 & 15 \\
\hline Number of consultations: cohort $2017^{\mathrm{i}}$ & 14 & 12 & 13 & 14 & 15 & 15 \\
\hline Individual index year cost: 2016 & 2007 & 1584 & 2506 & 2099 & 2622 & 2300 \\
\hline Individual index year cost: 2017 & 2061 & 1623 & 2340 & 2151 & 2774 & 2505 \\
\hline
\end{tabular}

Costs are observed during 2015-2019 and split by the index year cohort and the type of diagnostic imaging

Values are rounded to the nearest integer and corrected for inflation rates expressing all costs in 2019 prices in Switzerland (details in Supplemental Information)

${ }^{a}$ The number of patients is defined at the index year. However, for not all patients we have 4 years of observations

${ }^{\mathrm{b}}$ Average annual cost, summed by cohort. The total costs are the sum of ambulatory and in-hospital treatment costs

${ }^{\mathrm{c}}$ Average annual total cost split by patients with only one index imaging in 2016 (cohort 2016) or in 2017 (cohort 2017)

${ }^{\mathrm{d}}$ Average annual total cost per patient, split by patients in cohort 2016 or cohort 2017

${ }^{\mathrm{e}}$ Average annual total cost per patient, split by index year cohort 2016/2017 and relative to the subgroup of patients with comorbidities and inhospital treatment

${ }^{\mathrm{f}}$ Average cost per patient relative to the index year only, split by cohort 2016/2017

${ }^{\mathrm{g}}$ Costs for imaging studies are only reported for the index year

${ }^{\mathrm{h}}$ Annual average quantity of prescribed items per patients, split by index year cohort 2016/2017

${ }^{\mathrm{i}}$ Annual average number of consultations per patients, split by index year cohort 2016/2017 

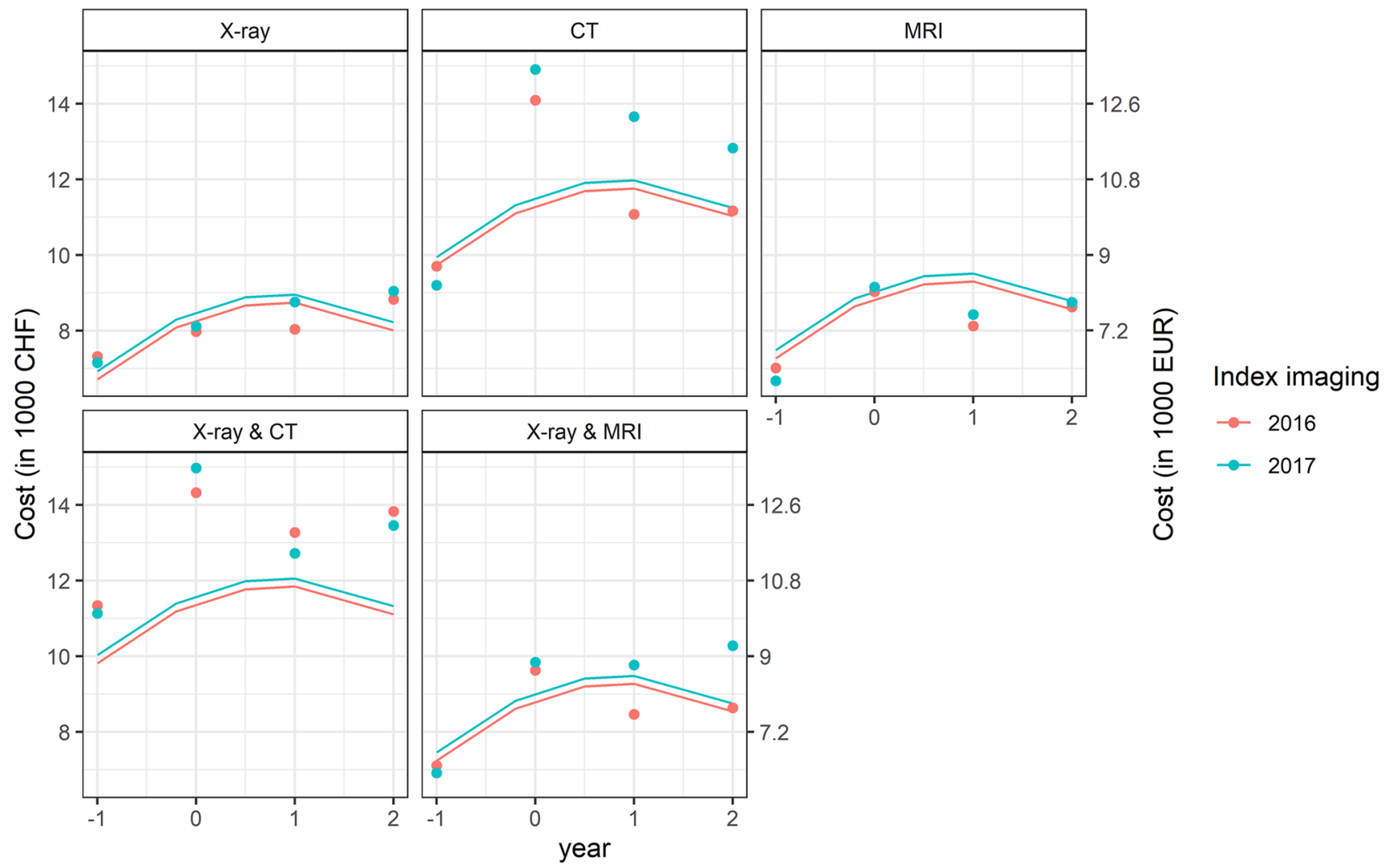

Fig. 2 Mean costs per patient depending on the kind of index imaging. Dots represent the mean costs per patient in 1000 Swiss Francs (CHF), left y-axis, and 1000 Euro (EUR), right y-axis. Curves represent the fitted line from the regression models. Red: index imaging year 2016, blue: index year 2017. CT: computed tomography; MRI:

magnetic resonance imaging. Year goes from -1 (one year before index imaging year) to 2 (two years after index year). Values are corrected for inflation rates expressing all costs in 2019 prices in Switzerland (details in Supplemental Information)

For all ages, the average relative difference was of $72 \%$ of the average costs for no LBP patients. Regarding the comorbidities groups, the following ones had greater estimates of costs for LBP patients compared to no LBP patients: cancer, 35,465 CHF (31,918 EUR) for LBP vs 20,269 CHF (18,242 EUR) for No LBP; neurological diseases 10,507 CHF (9456 EUR) LBP vs 9443 CHF (8499 EUR) no LBP; psychological diseases 4454 CHF (4009 EUR) LBP vs 4274 CHF (3847 EUR) no LBP; other diseases 2833 CHF (2550 EUR) LBP vs. 2330 CHF (2097 EUR) no LBP (Supplementary Information, Table S4).

\section{Discussion}

In this study, we reported patient characteristics and overall health care costs of patients with a radiological imaging for LBP in Switzerland. We found that a large proportion of insured persons had a radiological imaging of the spine and that this group contributes substantially to the health care costs. In our patient group of $>75,000$ patients, costs were

highest in patients with a CT imaging (alone or combination with X-ray) at patient level whereas, on an insurance level cost, were highest in patients with an MRI or X-ray imaging. LBP patients' costs were higher than those of the general insured at GM, especially the younger the patients were.

\section{Importance, background, and characteristics}

Imaging examinations of the lumbar spine are common in patients with LBP [22]. To improve quality of care and to limit unnecessary health care expenses and associated economic burden, many guidelines recommend imaging studies only if patients have "red flags" or a serious suspected pathology [10]. Although, some evidence suggests that many patients with LBP, seen in primary care, have a "red flag" [23] and thus justifies the high numbers of radiological imaging, there is a substantial proportion of inappropriateness in patient management and many initiatives call for a more prudent approach in patient care [11, 12]. In addition, evidence-based treatment of LBP patients was associated with lower treatment costs [24]. In our analysis, we included 
Table 3 Regression model analysing patient variables (fixed effects) affecting average cost per patient (in Swiss Francs)

\begin{tabular}{|c|c|c|c|}
\hline Variable $^{\mathrm{a}}$ & Estimates & $95 \%$ CI & $p$ \\
\hline Age & 101.68 & $(92.78,102.15)$ & $<0.001$ \\
\hline Male gender & -165.21 & $(-259.29,20.66)$ & 0.066 \\
\hline Medical services & 2540.37 & $(2340.71,2777.4)$ & $<0.001$ \\
\hline Comorbidity & 6178.18 & $(5876.76,6262.13)$ & $<0.001$ \\
\hline \multicolumn{4}{|l|}{ Area of residence (ref: French speaking) } \\
\hline Abroad & -1745.10 & $(-2608.81,-1235.45)$ & 0.005 \\
\hline German speaking & -863.76 & $(-945.23,-679.13)$ & $<0.001$ \\
\hline Italian speaking & -1034.81 & $(-1350.97,-729.56)$ & $<0.001$ \\
\hline \multicolumn{4}{|l|}{ Type of insurance (ref free choice model) } \\
\hline Network model & -944.77 & $(-1540,-573.26)$ & 0.009 \\
\hline Family physician model & -780.97 & $(-1057.51,-255.8)$ & 0.009 \\
\hline Telemedicine model & -974.19 & $(-1299.59,-485.27)$ & 0.001 \\
\hline \multicolumn{4}{|l|}{ Deductible (ref: 2500) } \\
\hline$\leq 500$ & 1794.48 & $(1910.94,2646.48)$ & $<0.001$ \\
\hline$\leq 1500$ & -66.17 & $(-294.7,611.82)$ & 0.815 \\
\hline Year $^{2}$ & -580.93 & $(-629.44,-573.26)$ & $<0.001$ \\
\hline Year & 1013.66 & $(996.7,1095.78)$ & $<0.001$ \\
\hline Imaging in 2017 (ref 2016) & 214.08 & $(58.85,349.44)$ & 0.015 \\
\hline \multicolumn{4}{|l|}{ Type of imaging (ref X-ray) } \\
\hline $\mathrm{X}$-ray $+\mathrm{CT}$ & 3101.69 & $(2369.36,3641.61)$ & $<0.001$ \\
\hline X-ray + MRI & 530.33 & $(247.06,639.81)$ & 0.006 \\
\hline $\mathrm{CT}$ & 3019.64 & $(2498.08,2997.51)$ & $<0.001$ \\
\hline MRI & 557.91 & $(341.41,591.8)$ & $<0.001$ \\
\hline \multicolumn{4}{|l|}{ Interaction (type of insurance and deductible) } \\
\hline Network model and deductible $\leq 1500$ & 593.90 & $(-283.79,886.23)$ & 0.181 \\
\hline Family physician model and deductible $\leq 1500$ & 489.54 & $(-518.17,810.39)$ & 0.216 \\
\hline Telemedicine model and deductible $\leq 1500$ & 431.28 & $(-514.49,795.63)$ & 0.283 \\
\hline Network model and deductible $\leq 500$ & -65.34 & $(-807.45,184.78)$ & 0.862 \\
\hline Family physician model and deductible $\leq 500$ & -36.89 & $(-917.86,15.61)$ & 0.906 \\
\hline Telemedicine model and deductible $\leq 500$ & -359.18 & $(-1132.54,-237.94)$ & 0.263 \\
\hline
\end{tabular}

Estimates and empirical 95\% confidence intervals (CI) were computed using case bootstrap with 100 resamples at patient level

${ }^{a}$ Mixed model with patients as random effects and correction for autocorrelation ARMA $(1,1)$. Patients with images in both index years were excluded from the analysis. All estimates are in Swiss Francs. Numbers of observations $=240,982$, numbers of patients/insured $=67,954$. Ref reference, $C T$ computed tomography, MRI magnetic resonance imaging, time was defined as 0 (index imaging), -1 (the year before index imaging), 1, 2 (first, second year after index imaging). Effect of time on costs was not linear (quadratic trend) with coefficients Year $^{2}+$ Year reported, that means the costs are first increasing then decreasing on year from index imaging patients with a radiological imaging of the spine as a surrogate for LBP. In the literature, the proportion of patients with LBP with a radiological imaging differs [22, 25] as well as the proportion of used imaging techniques, as it depends on the clinical setting. In line with our results, which are based on a sample of $12 \%$ of the Swiss population, MRI and $\mathrm{X}$-ray imaging are often the most common used methods [26]. In our cohort, distribution of both age and sex was similar compared to previous reports on LBP in Switzerland $[5,27]$. We found that, in our cohort, both the proportion of patients with a deductible $\leq 500 \mathrm{CHF}$ and insurance model without a gatekeeper (free choice of medical practitioner model) were higher compared to the general population [28]. In fact, the proportion in our study were, in the first case $76.5 \%$ vs. $56.5 \%$ and in the second case $40.3 \%$ vs. $29.8 \%$.

\section{Health care costs}

LBP contributes substantially to national health care costs. This is due to the combination of the high prevalence of LBP and the high individual costs for affected patients. In the United States, low back and neck pain account for the 


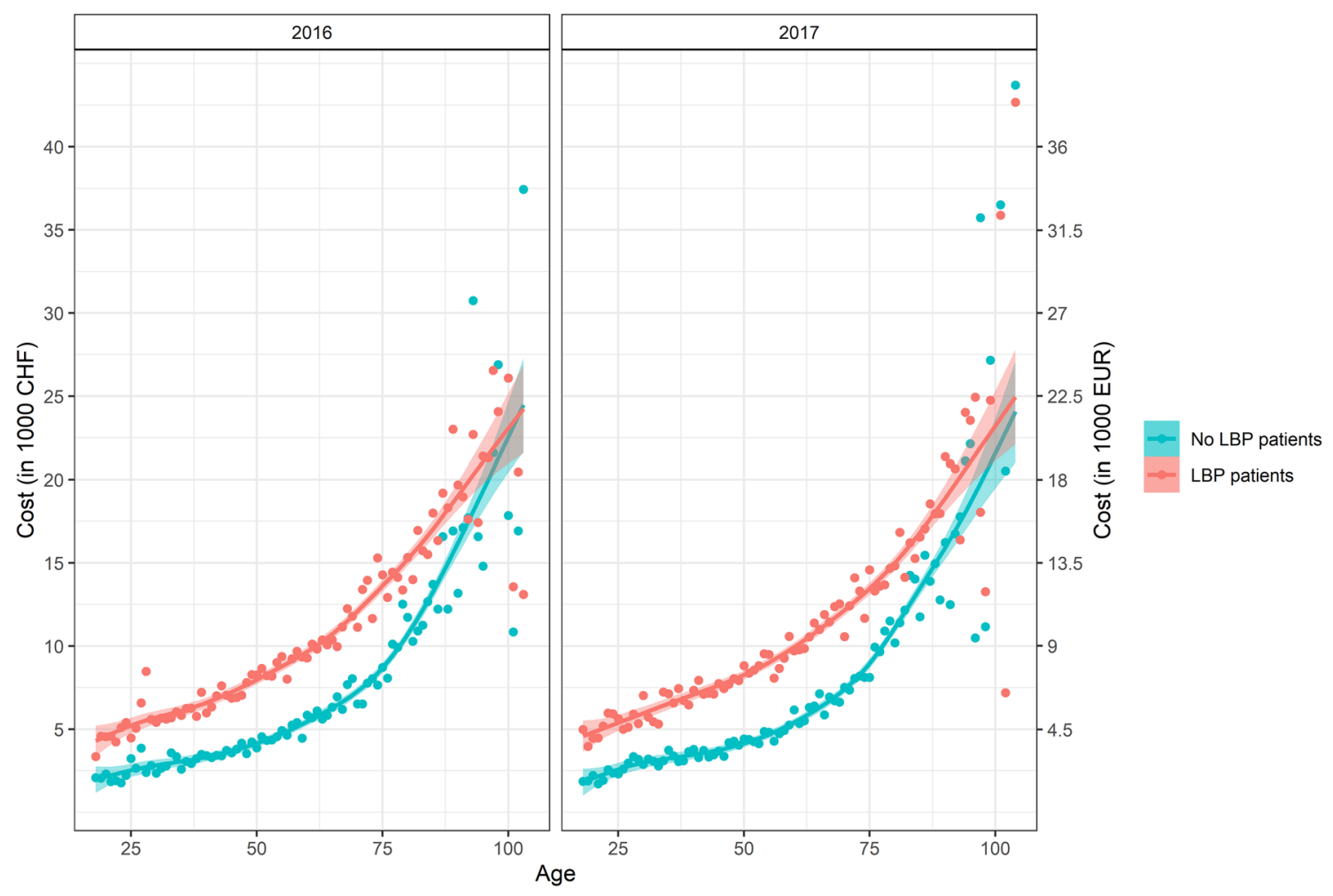

Fig. 3 Mean health care costs per patient, in 2016 and 2017 separately, by age (in years), of LBP patients compared to a comparable population, insured by GM, without LBP. For each age, average costs per patient are represented with points and lines represented the smoothed curves. Shaded areas represented the 95\% Confidence

third highest health care spending and expenses have been continuously increasing over the last decade [29]. Also in our analysis, index imaging in 2017 were associated with higher costs compared to 2016 and mean health care costs were higher over the entire observation period in patients with an index image in 2017 than in patients with an index image in 2016. At patient level, we found the highest costs for patients with CT imaging (CT alone or in combination with an X-ray). CT is indicated if bone structures are critical $[30,31]$ and patients in this subgroup had the highest rates of comorbidities, in-hospital treatments, and a higher mortality rate. In addition, at patient level, costs for pain medication, additional medications and also other medical services were highest in this group. In our patient group, a CT scan of the lumbar spine could be seen as a surrogate of a more severe overall health status compared to patients undergoing a MRI scan or a conventional X-ray and thus explaining the higher costs at patient level.

At health insurance level, due to the more frequent use of these imaging methods, costs were highest for patients with an MRI or X-ray examination. In contrast to CT imaging, MRI is preferred for investigations with focus on soft tissue structures like nerve or lumbar disc pathologies [32].
Interval of the fitted curves. Costs are expressed in 1000 Swiss Francs (CHF), left $y$-axis, and 1000 Euro (EUR), right $y$-axis, and corrected for inflation rates expressing all costs in 2019 prices in Switzerland (details in Supplemental Information)

Comorbidities, in-hospital treatments and mortality rates were lower compared to the subgroup with CT imaging and costs for pain medications, additional medications and other medical services were lower too.

For Switzerland, only sparse literature exists. Wieser et al. [8] reported total yearly costs for LBP of about 6.6 Billion euro in 2005 , which equals $6.1 \%$ of the national health care spending in 2005. Direct medical costs were estimated with 2.5 billion euro, and indirect costs (using a human capital approach) with 4.1 billion euro. This calculation relied on estimates based on self-declarations obtained by a survey among a convenience sample of the general population and reports LBP-associated costs only. However, a direct comparison with our data is not possible due to the different methodologies used and population studied.

In contrast, we were able to include in our study only patients with LBP who had received diagnostic imaging. Our study lacks of all health care costs of patients without an imaging study, thus our numbers underestimate the real economic burden of LBP in Switzerland. Furthermore, it should be considered that many patients bear LBP-associated costs themselves and thus these costs could not be included in our analysis [5]. With reference to the population insured 
by GM, an age-adjusted comparison of mean costs shows that patients with LBP have higher costs than the average insured person as long as they are younger than 90 years of age. The costs surpass the mean health care costs by $72 \%$, on average, and were higher the younger the patients were. Our findings could confirm findings in the literature, reporting that the mean costs for LBP patients surpass the costs of the general population $[4,33]$. Optimized preventive and therapeutic efforts should therefore, from a purely economic point of view, focus primarily on younger patient groups, where the greatest difference in health care costs compared to the general population can be observed. With increasing age, the prevalence of chronic diseases increases and there is a growing possibility that the presence of LBP has a potentiating interaction with concomitant diseases. Differentiated analyses are therefore needed to analyse the effect of LBP on health care costs as patients get older.

\section{Characteristics associated with costs}

Identifying patients with an increased risk of high costs is of utmost importance. By identifying the population at risk and specific subgroups of even higher risk, not only health care insurance companies, but all relevant parties in a health care system could improve allocation of efforts or could apply preventive measures in advance. We identified specific patient characteristics affecting patient health care costs. For some characteristics, for example comorbidities and use of other health care utilization, an explicit association with increased costs is understood. In addition, we could show that the area of residence, type of insurance and the level of deductibles were associated with increased or decreased costs. These findings are in line with evidence suggesting that low deductibles and an insurance model without any gatekeeper function are associated with higher costs, since managed care models in Switzerland seem to be more economic [34, 35]. With regard to comorbidities, we found a varying influence of the different comorbidities on health care costs. At the same time, this influence was partly even greater in the matched cohort of non-LBP patients. Further studies are therefore needed to investigate the complex interplay between comorbidities and health care costs in patients with LBP.

\section{Strengths and limitations}

In this study, we reported actual data on patient in a large group of $>75,000$ patients, provided by one of the biggest health care insurance companies in Switzerland. The knowledge of the distribution of used radiological imaging studies, patient characteristics and health care costs in this population, will improve strategies and future interventions fostering prudent patient care. In accordance with a recently published proposed guidance in reporting costs in patients with LBP [36], our study reported detailed descriptions of used methods and considered costs. We reported detailed patient characteristics including 34 different and well-defined comorbidities.

This study has some limitations. First, due to applicable regulations of GM, we could only analyse a random selected subset of $92 \%$ of all patients with LBP. However, due to the random selection of patients and the still high percentage of analysed cases (>90\%) the analysis is still representative for the population insured by GM. In addition, we are aware that GM insured only around $12 \%$ of the Swiss population and thus our data might not be representative for all insured people in Switzerland. Second, we could not totally exclude the chance, that patients with unspecific imaging codes had an imaging examination other than or exclusively for the lumbar spine. Third, we could only report the overall medical costs reimbursed by the health care insurer, therefore, we were unable to provide a full breakdown of all costs specific for LBP only. Finally, some aspects and findings of this study are limited to the specific characteristics of the Swiss Health system and the validity of these specific findings might not be extended to other countries.

\section{Conclusion}

In this study, we reported characteristics and overall health care costs for patients with a diagnostic imaging for LBP. Diagnostic imaging for LBP is common and costs for patients with LBP clearly surpassed the average health care costs of insured patients without LBP. Our findings confirm the economic burden of LBP and highlight the importance of ongoing efforts to improve prevention, diagnostic and patient care in patients with LBP.

Supplementary Information The online version contains supplementary material available at https://doi.org/10.1007/s10198-021-01397-8.

Author contributions Conceptualization, CB, TR, AP: methodology, SD and AP: software, SD and GP: validation, SD, CB, AP: formal analysis, SD: investigation, $\mathrm{CB}$ and $\mathrm{AP}$ : resources, TR: data curation, GP: writing - original draft preparation, SD and AP: writing - review and editing, SD, CB, GP, TR and AP: visualization, SD and GP: supervision, TR: project administration, SD and AP. All authors have read and agreed to the published version of the manuscript.

Funding Open access funding provided by University of Zurich. No funds, grants, or other support was received.

Availability of data and material Data are available on request due to privacy or other restrictions.

Code availability Code for data cleaning and analysis is available on requests. 


\section{Declarations}

Conflicts of interest The authors have no conflicts of interest to declare that are relevant to the content of this article.

Ethical approval Not applicable.

Consent to participate Not applicable.

Consent for publication Not applicable.

Open Access This article is licensed under a Creative Commons Attribution 4.0 International License, which permits use, sharing, adaptation, distribution and reproduction in any medium or format, as long as you give appropriate credit to the original author(s) and the source, provide a link to the Creative Commons licence, and indicate if changes were made. The images or other third party material in this article are included in the article's Creative Commons licence, unless indicated otherwise in a credit line to the material. If material is not included in the article's Creative Commons licence and your intended use is not permitted by statutory regulation or exceeds the permitted use, you will need to obtain permission directly from the copyright holder. To view a copy of this licence, visit http://creativecommons.org/licenses/by/4.0/.

\section{References}

1. Finley, C.R., Chan, D.S., Garrison, S., Korownyk, C., Kolber, M.R., Campbell, S., et al.: What are the most common conditions in primary care? System. Rev. Can Fam Phys. 64(11), 832-840 (2018)

2. Global, regional, and national age-sex specific all-cause and cause-specific mortality for 240 causes of death, 1990-2013: a systematic analysis for the Global Burden of Disease Study 2013. The Lancet 385(9963), 117-71 (2015). https://doi.org/10.1016/ S0140-6736(14)61682-2.

3. Hartvigsen, J., Hancock, M.J., Kongsted, A., Louw, Q., Ferreira, M.L., Genevay, S., Hoy, D., Karppinen, J., Pransky, G., Sieper, J., Smeets, R.J., Underwood, M., Lancet Low Back Pain Series Working Group: What low back pain is and why we need to pay attention. Lancet (London, England) 391(10137), 2356-2367 (2018). https://doi.org/10.1016/S0140-6736(18)30480-X

4. Luo, X., Pietrobon, R., Sun, S.X., Liu, G.G., Hey, L.: Estimates and patterns of direct health care expenditures among individuals with back pain in the United States. Spine 29(1), 79-86 (2004). https://doi.org/10.1097/01.Brs.0000105527.13866.0f

5. Back-Report Switzerland 2020. Rheumaliga Schweiz. https:// www.rheumaliga.ch/assets/doc/CH_Dokumente/blog/2020/ rueckenreport-2020/Rueckenreport-2020.pdf (2020). Accessed 01 March 2021.

6. Dagenais, S., Caro, J., Haldeman, S.: A systematic review of low back pain cost of illness studies in the United States and internationally. Spine J. 8(1), 8-20 (2008). https://doi.org/10.1016/j. spinee.2007.10.005

7. OECD. Health spending. https://data.oecd.org/healthres/healthspending.htm\#indicator-chart (2020). Accessed 01 July 2020.

8. Wieser, S., Horisberger, B., Schmidhauser, S., Eisenring, C., Brügger, U., Ruckstuhl, A., et al.: Cost of low back pain in Switzerland in 2005. Eur. J. Health. Econ. 12(5), 455-467 (2011). https://doi.org/10.1007/s10198-010-0258-y

9. Kim, L.H., Vail, D., Azad, T.D., Bentley, J.P., Zhang, Y., Ho, A.L. et al.: Expenditures and Health Care Utilization Among adults with newly diagnosed low back and lower extremity pain. JAMA Network Open 2(5), e193676-e (2019). https://doi.org/10.1001/ jamanetworkopen.2019.3676.

10. Oliveira, C.B., Maher, C.G., Pinto, R.Z., Traeger, A.C., Lin, C.C., Chenot, J.F., et al.: Clinical practice guidelines for the management of non-specific low back pain in primary care: an updated overview. Eur. Spine J. 27(11), 2791-2803 (2018). https://doi.org/ 10.1007/s00586-018-5673-2

11. Smarter medicine - Choosing Wisely Switzerland https://www. smartermedicine.ch/de/top-5-listen/ambulante-allgemeine-inneremedizin.html (2020). Accessed 30 January 2020.

12. Choosing Wisely - North American Spine Society http://www. choosingwisely.org/clinician-lists/nass-opioids-for-acute-or-chron ic-low-back-pain/ (2020). Accessed 30 January 2020.

13. Gore, M., Sadosky, A., Stacey, B.R., Tai, K.S., Leslie, D.: The burden of chronic low back pain: clinical comorbidities, treatment patterns, and health care costs in usual care settings. Spine 37(11), E668-E677 (2012). https://doi.org/10.1097/BRS.0b013 e318241e5de

14. Swiss National Bank. Foreign exchange rates -Year. https://data. snb.ch/en/topics/ziredev\#!/cube/devkua Accessed 8 August 2021.

15. Bill, M., Meyer, D., Telser, D.H.: Aktualisierung der PCG-Liste für den Schweizer Risikoausgleich. Studie im Auftrag des Bundesamts für Gesundheit BAG. https://www.bag.admin.ch/dam/ bag/de/dokumente/kuv-aufsicht/pus/risikoausgleich/corrigendun. pdf.download.pdf/Polynomics_Uni_Basel_Aktualisierung_PCG_ Schlussbericht_2019-01-22.pdf (2019). Accessed 30 January 2020

16. Organization for Economic Cooperation and Development. Consumer Price Index: All Items for Switzerland [CHECPIALLQINMEI]. FRED, Federal Reserve Bank of St. Louis. https://fred.stlou isfed.org/series/CHECPIALLQINMEI. Accessed 8 August 2021.

17. Koechlin, F., Konijn, P., Lorenzoni, L. et al.: Comparing Hospital and Health Prices and Volumes Internationally: Results of a Eurostat/OECD Project. OECD Health Working Papers 75 (2014). OECD Publishing, Paris. https://doi.org/10.1787/5jxznwrj32 mp-en.

18. Purchasing power parities (PPPs), price level indices and real expenditures for ESA 2010 aggregates. Eurostat. https://ec.europa. eu/eurostat/databrowser/view/prc_ppp_ind/default/table?lang=en. Accessed 8 August 2021.

19. Todesfälle nach Alter und Geschlecht, 1970-2019. Federal Statistical Office. https://www.bfs.admin.ch/bfs/en/home/stati stics/population/births-deaths/deaths.assetdetail.13187457.html (2020). Accessed 01 October 2020.

20. Ständige Wohnbevölkerung nach Alter, Geschlecht und Staatsangehörigkeitskategorie, 2010-2019. Federal Statistical Office. https://www.bfs.admin.ch/bfs/en/home/statistics/population/effec tif-change/age-marital-status-nationality.assetdetail.13707177. html (2020). Accessed 01 October 2020.

21. Van der Leeden, R., Meijer, E., Busing, F.M.: Resampling multilevel models. In: de Leeuw, J., Meijer, E. (eds.) Handbook of Multilevel Analysis, pp 401-433. Springer, New York (2008)

22. Jenkins, H.J., Downie, A.S., Maher, C.G., Moloney, N.A., Magnussen, J.S., Hancock, M.J.: Imaging for low back pain: is clinical use consistent with guidelines? A systematic review and metaanalysis. The Spine Journal 18(12), 2266-2277 (2018). https:// doi.org/10.1016/j.spinee.2018.05.004

23. Henschke, N., Maher, C.G., Refshauge, K.M., Herbert, R.D., Cumming, R.G., Bleasel, J., et al.: Prevalence of and screening for serious spinal pathology in patients presenting to primary care settings with acute low back pain. Arthritis Rheum. 60(10), 3072-3080 (2009). https://doi.org/10.1002/art.24853

24. McGuirk, B., King, W., Govind, J., Lowry, J., Bogduk, N.: Safety, efficacy, and cost effectiveness of evidence-based guidelines for 
the management of acute low back pain in primary care. Spine 26(23), 2615-2622 (2001)

25. Chou, R., Qaseem, A., Owens, D.K., Shekelle, P.: Physicians ftCGCotACo.: Diagnostic Imaging for Low Back Pain: Advice for High-Value Health Care From the American College of Physicians. Ann. Intern. Med. 154(3), 181-189 (2011). https://doi.org/ 10.7326/0003-4819-154-3-201102010-00008

26. Downie, A., Hancock, M., Jenkins, H., Buchbinder, R., Harris, I., Underwood, M., et al.: How common is imaging for low back pain in primary and emergency care? Systematic review and metaanalysis of over 4 million imaging requests across 21 years. Br. J Sports Med. 54(11), 642-651 (2020). https://doi.org/10.1136/ bjsports-2018-100087

27. Kolb, E., Canjuga, M., Bauer, G.F., Läubli, T.: Course of back pain across 5 years: a retrospective cohort study in the general population of Switzerland. Spine 36(4), E268-E273 (2011). https://doi.org/10.1097/BRS.0b013e3181f324b5

28. Statistik der obligatorischen Krankenversicherung Ausgabe 2018. https://www.bag.admin.ch/bag/de/home/zahlen-und-statistiken/ statistiken-zur-krankenversicherung/statistik-der-obligatorischenkrankenversicherung.html (2018). Accessed 01 July 2020.

29. Dieleman, J.L., Baral, R., Birger, M., Bui, A.L., Bulchis, A., Chapin, A., et al.: US spending on personal health care and public health, 1996-2013. JAMA 316(24), 2627-2646 (2016). https:// doi.org/10.1001/jama.2016.16885

30. Lateef, H., Patel, D.: What is the role of imaging in acute low back pain? Current reviews in musculoskeletal medicine. Curr. Rev. Musculoskelet. Med. 2(2), 69-73 (2009). https://doi.org/10. 1007/s12178-008-9037-0
31. Bradley, W.G.: Low Back Pain. AJNR Am. J. Neuroradiol. 28(5), 990-992 (2007)

32. Sheehan, N.J.: Magnetic resonance imaging for low back pain: indications and limitations. Ann. Rheum. Dis. 69(01), 7-11 (2010). https://doi.org/10.1136/ard.2009.110973

33. Ivanova, J.I., Birnbaum, H.G., Schiller, M., Kantor, E., Johnstone, B.M., Swindle, R.W.: Real-world practice patterns, health-care utilization, and costs in patients with low back pain: the long road to guideline-concordant care. Spine J. 11(7), 622-632 (2011). https://doi.org/10.1016/j.spinee.2011.03.017

34. Schwenkglenks, M., Preiswerk, G., Lehner, R., Weber, F., Szucs, T.D.: Economic efficiency of gatekeeping compared with fee for service plans: a Swiss example. J. Epidemiol. Community Health 60(1), 24-30 (2006). https://doi.org/10.1136/jech.2005.038240

35. Reich, O., Rapold, R., Flatscher-Thöni, M.: An empirical investigation of the efficiency effects of integrated care models in Switzerland. International journal of integrated care. Int. J. Integr. Care 12:e2 (2012). https://doi.org/10.5334/ijic.685.

36. Zemedikun, D.T., Kigozi, J., Wynne-Jones, G., Guariglia, A., Roberts, T.: Methodological considerations in the assessment of direct and indirect costs of back pain: A systematic scoping review. PLoS ONE 16(5), e0251406 (2021). https://doi.org/10. 1371/journal.pone.0251406

Publisher's Note Springer Nature remains neutral with regard to jurisdictional claims in published maps and institutional affiliations. 